\title{
A View of the Symbolic-experiential Family Therapy of Carl Whitaker through Movie Analysis
}

\section{Pinar Cag ${ }^{a}$}

Middle East Technical University

\author{
Nilufer Voltan Acar \\ Hacettepe University
}

\begin{abstract}
The movie "Ya Sonra" is evaluated in respect to the basic concepts and principles of symbolic-experiential family therapy. Carl Whitaker, who called his approach "Psychotherapy of Absurdity" mainly emphasized the concepts of absurdity, experientiality, and symbolism. Based on the hypothesis that film analysis supports and develops theoretical information, this study aims to reveal the theoretical perspective of symbolic-experiential family therapy, and through the method of film analysis, exemplify the assumptions, perspectives, and emphases of therapy. Emotional deadness, pathology as a symptom of development, the focus person of the problem in the family, marriage greater than its parts, blind marriage, flexibility of roles, the role of therapist, seeing family and client, the objectives of therapy, and the techniques used in therapy are among the theoretical concepts of symbolic-experiential family therapy. To this end, these topics were addressed in the movie "Ya Sonra," which is about a woman in her seventh year of marriage who starts to feel that she does not belong in her marriage with her spouse and that she is seen as insignificant by her spouse. Therefore, she becomes identified as the patient in the family. The sensitivity of the spouses increases as the problem becomes more serious, eventually leading her to leave the house. The breakdown of communication between the spouses during the ensuing process finally results in divorce, due to a gradual increase in misunderstandings between the two. The previously described concepts were exemplified through analysis of the film. As a conclusion, it is believed that this study can serve as a resource to specialists by supporting the theoretical information concerning symbolicexperiential family therapy and exemplifying this approach in practice through the method of movie analysis.
\end{abstract}

Keywords: Symbolic-experiential family therapy $\bullet$ Carl A. Whitaker $\bullet$ Film • Family therapy

a Corresponding author

Pınar Cag, Learning and Student Development Office, Middle East Technical University, Ankara, Turkey Research areas: Marital satisfaction; Marriage and spousal support; Marriage and family therapy Email: cpinarametu.edu.tr

b Prof. Nilüfer Voltan Acar (PhD), Department of Educational Sciences, Psychological Counseling and Guidance, Faculty of Education, Hacettepe University, Ankara, Turkey Email: nvalahacettepe.edu.tr 
The background of family therapy resembles an exciting novel. Several models of family therapy abundantly suggest creative ideas and new techniques. The leaders in creativity, such as Minuchin, Ackerman, Whitaker, Haley, and Satir are quite distinct in this field (Carson, 1999). It can be suggested that experiential theories are more prominent in terms of creative ideas. Although it is called non-theoretical experiential therapy, this approach facilitates creative experiences in families. Creative, spontaneous, non-rational experience is a significant objective of experiential family therapy (Piercy, Sprenkle, Wetchler, \& Associates, 1996 as cited in Carson, 1999). According to experiential therapists, "This therapy depends on the interactive process of intellectual understanding, metaphoric language, and personal interaction" (Keith, 1982, p. 331 as cited in Bermudez, 1997). The main objective here is growth (Neill \& Kniskern, 1982; Mitten \& Piercy, 1993; Whitaker \& Bumberry, 1988 as cited in Bermudez, 1997).

Experiential family therapy evolved in the decades following the humanistic psychology movement. At first, founders of the approach were very interested in the structures of treatment based on experience. Certain theorists of experiential family counseling such as Carl Whitaker relied more on their own characters, creativity, and spontaneity in respect to timely and effective responses in their studies with families. The most significant roles adopted by these therapists include the roles of process facilitator and source person (Gladding, 2012). Whitaker appreciates and adopts the absurd aspects of life.

One of the experiential theorists who defends the suggestion "One can only learn through experience" is Carl Whitaker (Whitaker \& Bumberry, 1988, p. 73 as cited in Bermudez, 1997). Whitaker was born on a farm in New York in 1912, grew up as a very shy child with only his family in his social circle. Whitaker started to lay the foundations of symbolic-experiential family therapy and its theoretical structure (Martin, 2011). According to Whitaker and Keith (1981), a right-brain oriented, non-rational experience is an indicator of health in the family for the therapist. Furthermore, a part of family problems stems from a lack of creative problem-solving skills in the family (as cited in Carson, 1999). His hypotheses and insecure theory, which was suspect to many, caused people to refrain from using this approach from time to time.

People have certain needs and strong urges to understand and regulate their environment. Theories assist therapists with controlling and regulating the environments of people. Whitaker went beyond the known definition of "theory" by theorizing even the unknown of unknown (Smith, 1998) Therefore, he suggested an unusual theory defining different concepts which he did not establish on any expected structure. Whitaker used the concept of absurdity several times in his theory. The basic hypothesis of this theory is to ensure that family members establish a relationship with their own absurdities without restriction through emotional means. While working with families, Whitaker teased them through free behavioral and emotional means to provoke them, and he supported the families in communicating with their own absurdities. Whitaker put absurdity forward in studies on the subconscious and emphasized the importance of spontaneity during therapy. Such absurdity and unexpectedness provide significant benefits in achieving the goals of therapy. This is used to divide the problematic situations of communication, change the interaction and perception of the therapeutic process, support and open the reasoned "observer" role of the right hemisphere of the brain, and overcome therapeutic deadlock and blockage (Watzlawick, 1974 as cited in Cullin, 2008).

As a family therapist, Whitaker was quite intuitive and natural; he was not a constructivist. At this point, unlike many therapists, it is impossible to separate Whitaker's approach from his personality (Gladding, 2007). Therefore, he rejected giving instructions to make a change in families. Instead, he carried out a non-theoretical and spontaneous therapy process in which he utterly used his own personality. Whitaker assumed that what motivates change in families is experience rather than education. Another concept emphasized by Whitaker is symbolism. One of the main functions of the brain cortex is obstruction. According to Whitaker, several of the experiences a person has continue in the subconscious with this obstruction, and the best method to reach these experiences is to be symbolic. What Whitaker meant by symbolic is that a thing or process embodies multiple meanings (Gladding, 2007). Whitaker shared his "crazy" thoughts with families at the same time he studied them so that he could support them in realizing that their lives were not as bad as assumed and they could be stronger against the problems of life. As he shared his thoughts, he often shared from his authentic identity and personality so as to lead families to take their cue from him and become free (Dhanesar, 2006). Whitaker's approach has a structure which is difficult to learn due to specificity to his own personality, its non-theoretical structure, and the emphasis on characteristics such 
as intuitivism, creativity, and symbolism. This is why the direction which the therapy was headed became blurred and started to lose its popularity after Whitaker's demise. Currently, defenders of the therapy have gone on to develop this therapy within post-modernism. Symbolic-experiential family therapy remained in the theoretical stage due to the scarcity of literature concerning it as well as the rapid changeability of its structure based on the personality traits of the therapist. It could not be further grounded as clear research could not be conducted on the practice and effectiveness of the therapy.

The purpose of experiential therapy is to provide experience to clients and then create an environment to reflect this experience in their life (Banker, 2008). Therefore, experiential therapies are difficult to apply and operate. As compared to behavioral therapies, it is more difficult to research the effectiveness of experiential methods. Consequently, there are a limited number of research studies in general on the outcomes and processes of experiential approaches (Mitten \& Connell, 2004). Based on these grounds, it is assumed that a study on experiential therapies using a qualitative method known as film analysis, while providing difficulty for empirical research, can shed light on the field. Therefore, as well as reviewing the theoretical structure of symbolic-experiential family therapy, reinforcing its theoretical importance by the method of film analysis also holds importance.

In a general sense, the basic building block of all films is the human being. Therefore, each movie presents personality traits of humanity while also constituting an information source concerning the concealed spiritual worlds of individuals (Horzum, 2011). Both films and novels can be used for educative purposes so as to develop new perspectives and ideas towards a particular situation or incident (Dermer \& Hutchings, 2000). Several subjects such as culture, class, gender, power, and sexual orientation can be discovered through films; the variability in movies and its variety of characters can offer the opportunity to discover a perspective of the world in a general sense even in just a brief scene (Dermer \& Hutchings, 2000).

One of several reasons for using films in therapy is the fact that they can offer variety and variability from several perspectives (Dermer \& Hutchings, 2000). Therefore, it is not a new practice to use films in psychological counselor education (Gladstein \& Feldstein, 1983 as cited in Villalba \& Redmond,
2008). Upon literature review of various professional education orientations on psychological counseling, films are seen to have been used in various fields such as ethics, psychopathology and diagnostics, group study, sensitivity to individual differences, and skills acquisition (Chambliss \& Magakis, 1996; Koch \& Dollarhide, 2000; Pinterits \& Atkinson, 1998 as cited in Villalba \& Redmond, 2008).

In selecting an appropriate film for film analysis studies, the ability to establish the film on therapeutic theoretical ground is important. Therefore, selecting a film which includes certain family patterns and the unfolding of these patterns (Wilson, Blake, Taylor, \& Hannigs, 2013) was taken into consideration as in the previous studies. To this end, the film "Ya Sonra" was selected with the opinion that it contains patterns convenient for adapting Whitaker's symbolic experiential family therapy. The scenes from the film which were estimated to set an example of Whitaker's approach were selected by researchers, and a general evaluation was made for these scenes. To this end, the scenes which can be addressed from the perspective of the Whitaker approach were explained based on the congruence with theoretical infrastructure. Starting from this point of view, basic explanations were first made regarding theoretical information and then a general evaluation of the married couple in the film was made using the Whitaker family therapy approach. The scenes which were consistent with the theoretical information were addressed and interpreted. In summary, the method constituted gathering the examples concerning Whitaker's symbolic experiential family therapy, an evaluation of the family in general, and then an analysis of the explained scenes.

\section{Symbolic-Experiential Family Therapy}

Symbolic-experiential family therapy is a nontheoretical and pragmatic approach which unlike several other therapies is not structured. It is important for the therapist to use their own personality, spontaneity, and creativity in symbolicexperiential family therapy. This approach focuses on emotions, and by establishing an efficient bond with the family, it holds importance for revealing emotions. Its symbolism, non-verbal methods, employment of games, and use of an assistant therapist are aspects which differentiate symbolicexperiential family therapy (Goldenberg \& Goldenberg, 2008). Marriage and family therapies employ more creative techniques and methods similar to symbolic experiential family therapy, and the therapist interacts directly with family members. 
Within this process, the therapist participates using their own personality as well as their self-reflection and involvement. This has critical importance in gathering family members and having a more entertaining time; the interactive style of the therapist also demonstrates the importance of firsthand interaction to family members (Thompson, Bender, Cardoso, \& Flynn, 2011).

While explaining his theory and teaching his students, Whitaker stated that being themselves at all times, feeding from their own creativity and surrendering themselves to the process as it is with all of their absurdities and naturalness is sufficient for studying with families (Sugarman, 1987). Whitaker went beyond the known definition of theory and theorized even the unknown of unknown. Because of this, he suggested an uncommon theory, defined a different structure, and established his theory on an expected structure. Whitaker used the concept of absurdity several times in his theory. While studying with families, Whitaker provoked them with free behavioral and emotional methods in order to support them with communication using their own absurdity. Such absurdity and unexpectedness proved a major benefit for the achievement of the goals of therapy. As a family therapist, Whitaker is quite intuitive and natural; he is not a structuralist. Therefore, he rejected giving instructions to ensure change in families and he carried out a nontheoretical, spontaneous therapeutic process in which he utterly used his own personality (Smith, 1998). Whitaker stated that he was influenced by psychodynamic theory based on the opinion that there are certain processes lying in the human subconscious and these can only be revealed symbolically. Whitaker also emphasized the concept of awareness in his therapy and mentioned that awareness has an ego-developing trait as well as the existence of a transference component. According to Whitaker, people refer their emotional attributions from the past onto their current spouses. In addition to this, symbolic-experiential family therapy researches the symptoms of the family in wider generations of the family, 2 to 3 generations retrospectively, and defends the hypothesis that their past experiences affect their current family patterns. This therapy also aims at receiving information from the dreams and fantasies of families with the assumption that these can help reach symbolic parts and signs. The fact that Whitaker considers experience important rather than education indicates that his therapy is based on phenomenological, experiential, and existential origins. Whitaker also places importance to the "here and now" which is among the basic principles of existential and humanistic approach. He focuses on the current experience and what is happening in this moment rather than the past or future. According to Whitaker, marriage is greater than its parts (Whitaker, Greenberg \& Greenberg, 1979 as cited in Martin, 2011). Based on this point of view, it can be possible to state that Whitaker took inspiration from Gestalt therapy through the opinion that the whole is more than the sum of its parts.

The educative aspect of Whitaker's therapy has a continuous basis. He had technical observations and ideas about the nature of psychotherapy; he had a lively, active, and interested approach in his family counseling studies for both individuals and married couples. His orientation within the counseling process was based on his subjective experiences and the creativity of his experiences. He did not depend on any systematic doctrine or written rules of any formal system. In this aspect, it is possible to say that the majority of traits which distinguish Whitaker from other clinicians and made him capable is based on his creative world and self-identity (Neill \& Kniskern, 1989). It is difficult to put this structure, which is unique to Whitaker, into practice. According to Whitaker, symbolic-experiential family therapy cannot possibly be learned in a direct intellectual context. It can only be learned through experience (Mitten, 1996). It has been mentioned in the literature that Whitaker's approach has components which strongly comply with the postmodern structure (Smith, 1998). Family therapy has started to increasingly be influenced by postmodernism and structuralism. System theory serves as a bridge in the transmission to postmodern thought. Family therapy was developed by psychiatrists who were not happy and could not be satisfied with individual therapy. They progressed with the postmodern thought of system theory in family therapy (Braderick \& Schrader, 1991 as cited in Smith, 1998). When Whitaker realized he would not be satisfied with individual therapy process, he started to study with families. When he started to study with families, he accepted the importance of systematic thought in family interactions to a higher degree. Upon reviewing the postmodernist perspectives of Whitaker, the first ones that can be seen are symbolism, experientialism, and the subjective nature of experiences, all of which are in good harmony with the personal and subjective facts of postmodernism. Secondly, the nontheoretical structure of Whitaker's approach, his lack of confidence in theories, and the fact that he found subjective fact more important also complies 
with subjectivity, which is the basic building block of postmodernism. Thirdly, it is assumed that the use of intuitivism in Whitaker's therapy is basically the charm of postmodernism, and intuitivism adds a post-modernistic flavor which is rightbrain oriented, personal, and subjective by nature. Fourthly, the overemphasis made by Whitaker on the therapist themselves in their approach is strongly in compliance with the recreational component of postmodern thought. In addition to all of these, the majority of therapeutic techniques adopted by Whitaker such as war for initiative, withdrawal, language of options, co-therapist, consultation, and termination are in good harmony with the postmodern paradigm (Smith, 1998).

- The main focus of this therapy is not to extinguish family symbols but to rearrange and reform these symbols (Mitten, 1996). Starting from this point of view, it is assumed that the experiences, emotions, and feelings of the individual are assumed to be the strength of their symbolic worlds. It can be mentioned that these experiences provide clients and therapist with an opportunity for self-improvement. The basic principles of this approach are as follows (Kempler, 1981 as cited in Martin, 2011):The symbolic scope of family requires study.

- In therapy sessions, the nature of new experiences should be tried.

- The therapist has to ensure complete participation and sharing in order to achieve the goals in a group.

In this therapy, the unique family symbols which are hidden beneath personal and familial development are focused on (Connell et al., 1999 as cited in Martin, 2011). Therefore, an inexperienced therapist should know that the meanings behind these symbols may change as the therapy progresses, and they should study by learning certain principles. Therapy makes several assumptions on the formation of human potential, marriage, life, and growth-development. Some of these are given below:

- Every individual and family has the capacity to develop, yet they may not have hope in maintaining it.

- Every individual is capable of selecting how to choose their life, yet the majority of these choices are based on their experiences with their families.

- All individuals have the potential to grow and develop. Whitaker believed "humans are merely particles of families" (Connell et al., 1999 as cited in Martin, 2011). People develop their values, beliefs, cultural identities, and sensitivities in their relationships and they can reform and change them. This leads to the hypothesis that people are similar rather than different and everyone seeks development.

- For family members, the protection, guarding, and maintenance of their own sensitivity, or identity of self, while at the same time belonging to the family is important. This model considers the influence of the family on themselves, and it naturally supports the development and growth of the individual by helping them protect themselves. At this stage, the therapist encourages the personal growth of the individual to help maintain it, and ensures that the family perceives the development of this person as the development and growth of the family at the same time.

\section{Evaluation of Film "Ya Sonra" in Respect to Symbolic-Experiential Family Therapy}

The use of films as a therapeutic instrument has been put on the agenda in the literature in recent years. Various researches, in which movies are used as both a method of intervention in psychotherapy and an instrument in the education of psychotherapists, are found in the world literature. Movies are stated to be strong therapeutic metaphors and they consist of components which strengthen the relationship between therapist and client, intensify the emotions of clients, and increase the awareness concerning their internal difficulties. Films help individuals solve their problems by allowing the individual to gain an outsider perspective to their problem, generating alternative perspectives to problems for which they could not previously find a solution, giving meaning to their problems, and developing new and functional skills for overcoming issues (Alexander \& Waxman, 2000; Hesley \& Hesley, 2001 as cited in Durak \& Fişığlu, 2007; Dermer \& Hutchings, 2000).

Films can be used as positive educational instruments (Wedding \& Niemiec, 2003). The employment of films in education, generally or specifically, in family counseling education has been developed. It can be seen that studies conducted through movies in the area of family counseling in particular prove beneficial to students with conceptualization and with understanding the concept of the family system. It also provides both students and educators with different perspectives concerning theoretical information (Nadir, 2013). 
Another advantage of using films in education is the opportunity to probe, understand, and observe non-verbal behaviors in addition to verbal behaviors (Shepard \& Brew, 2005 as cited in Nadir, 2013), which is important for discovering non-verbal messages in educational fields such as psychological counseling and psychology.

Movies can be used therapeutically to create professional objectives in the area of psychological counseling and guidance as well. Popular media and films can be used for educative purposes as well as for acquiring professional goals. While Kelly (1998) used silent film scenes to teach complicated syntax to deaf adults, Watson and Van Etten (1997) used films to change and understand attitudes about childhood obstacles. Nugent and Shaunessy (2003) used films in on-the-job training delivered to teachers for understanding the needs and characteristics of child prodigies. Madan-Bahel (2005) referred to films for teaching important points and creating a discussion for a sexual health program, while Stincfield (2006) used films to teach systematic thinking (cited in Powell, 2008). Similarly, it is aimed in this study to give better meaning to the infrastructure of the theory and shed light on students, professionals in the field, and educators as well.

This part of the study was exemplified using implementation of symbolic-experiential family therapy implementation through the movie analysis method. Exemplification of the concepts of Whitaker's symbolic-experiential family therapy, which have been explained in this article, was attempted through analysis of the film "Ya Sonra" so as to support the theoretical information.

Plot: General information about the film ${ }^{1}$ :

Film: "Ya Sonra"

Production: 2010-Turkey

Genre: Drama, Comedy, Romantic

Running Time: 105 minutes

\section{Director: Özcan Deniz}

Cast: Ayşen Gruda, Deniz Çakır, Cezmi Baskın, Naz Elmas, Barış Falay, Özcan Deniz, Didem Erol, Janset Paçal, Ragip Savaş, Fatma Toptaş, Erdem Akakçe, Mehmet Ulay, Aliye Uzunatağan, Bülent Seyran, Mehmet Aslan, Atakan Ilgazdağ, Altuğ Yücel, İsmail Düvenci

\section{Scenario: Özcan Deniz}

Cited from the introduction of the film on its website.
Producer: Ercan Deniz, Sinan Tekin, Vural Turunç

Plot: Didem and Adem had a great love. They flirted for 11 years before their marriage, and have been married for 7 years. Didem is an architect in a company. Adem is a veterinary in his own clinic. By the seventh year of their marriage, which started with a deep love, they find there is a communication gap increasing with the residual effects of the past. As a person who is more connected to the social world than his own home, Adem plays a character who becomes increasingly more selfish and has difficulty giving the attention and love his spouse longs for. Adem has exceedingly started to live for himself and become selfish whereas Didem has started to question her marriage by mentioning her discontent with the situation. Adem could not exactly give a response to Didem who was trying to talk about their problems and seek solutions. This led to deteriorating issues and eventually, divorce.

In this study, examples concerning concepts in symbolic-experiential family therapy were gathered and the family was first generally evaluated. Afterwards, the scenes concerning therapy were explained and analyzed.

\section{Evaluation of Film through Symbolic- Experiential Family Therapy and Analysis of Scenes}

Upon evaluation of the film, examples concerning emotional deadness, pathology as a symptom of development, the focus person of the problem in the family, a marriage greater than its parts, blind marriage, and flexibility of roles, which are included in Whitaker's approach, were seen in various scenes. The analysis of the film is presented with Whitaker's approach in the framework of scenes concerning each one of these aspects. In this therapy, the majority of which is postmodernist, certain concepts are addressed for use in the film analysis. These are emotional deadness, pathology as a symptom of development, focus person of the problem in the family (identified patient, or IP), marriage greater than its parts, blind marriage, and flexibility of roles.

Emotional Deadness: Whitaker's approach is based on the hypothesis that individuals are not aware of their emotions, or that they are aware of their emotions but suppress them within the family. As individuals who behave like this within the family do not realize or reveal their new emotions, emotional deadness occurs in the family. This shows its symptoms on the family members. When 
emotional deadness has occurred in the family, each individual grows distant from each other and engage in things outside the family. Such behaviors decrease the functionality of the family. Therefore, family members are motivated to interact with each other and expressly state their emotions (Gladding, 2007).

At the beginning of the film, Adem and Didem sit at a bar with an all-male group of Adem's friends . The subject of marriage is brought up and Adem says to his 40-year old bachelor-friend who wants to get married, "Why would you get married, are you insane? Do you want to get married to make your life fall apart?" In response to this reaction, Didem is petrified. Thereafter, she keeps her distance from Adem. While they are in the car going back home, Adem apologizes, yet Didem's resentment does not lessen. Adem cannot understand why Didem continues to keep her distance even though he has apologized, and without regard to his spouse's resentment, says, "Come on love, I don't want to have a quarrel with you. I am going to be sick, make me that nice soup of yours," and avoids the subject. Didem's resentment flares up even more since no attention was paid to it. At this stage, Didem suppresses her emotions to prevent the situation from getting worse and continues with her marriage.

For the second example, Adem comes home with his friends to watch a football game unannounced while Didem, who has a very important presentation at work the next day, is working on her drawing at home. Didem pulls Adem over to the side and tells him he doesn't care about her or her job at all. She gets angry with him for his thoughtless acts, yet Adem again avoids the situation by saying, "You can sit down and work, and we won't disturb you." Didem suffers another great disappointment and remains silent since she has no solution. She feels even more hopeless as she cannot find a solution even though she mentioned her resentment with anger. She retreats. At this stage, the emotional deadness that slowly begins to form between the couple can actually be seen through the pattern of incident and increasingly wider communication gap. At this stage, Didem grows distant from her marriage and throws herself into her work. She speaks less with Adem while Adem continues to further pursue his interests in his friends and business.

Pathology as Indicator of Development: Whitaker thought of pathology as an indicator of development. The pathology and non-functionality of a family member is evaluated as healthy. The identified patient (IP) is often the person who has accepted to be the "block" in the developmental process. Therefore, the IP is usually the healthiest member of the family (Malone, Whitaker, Warkentin, \& Felder, 1961 as cited in Martin, 2011). The opinion that each individual has the potential to become a patient is more prominent as opposed to labeling the identified patient in the family as "the patient" (Whitaker, 2000). Here, the focus person is not the identified patient; the symptom is taken from the identified patient and extended to the entire family. What is important at this stage is to minimize the role of scapegoat in the family. The responsibility and symptoms of the scapegoat can be taken and extended to all family members. At this stage, usually the person who applied for the therapy is the one who accepts being unhealthy and reaches a sufficient level of despair in respect to problem's solution. Therefore, they become the one who create development and change in the family.

Upon addressing this aspect, Didem appears to be in the role of identified patient in the film. According to Adem, their marriage is non-problematic as Adem can go to the gym for exercise, he can meet his friends whenever he wants, and he can allocate time for his business. In short, he can behave on his own without considering the awareness of establishing a mutual life. Didem increasingly shows more evidence of anger and fury. She retreats more as she cannot see anything in return for her anger and fury, turning to her inner world. At this stage, Didem is the party who complains about the situation and is considered by her spouse to be the one who perceives and behaves as if there is a problem when there is none. In other words, the identified patient is Didem. Upon looking at the scenes in the film, the scene at which the identified patient, Didem, acts in the most impulsive manner is when Didem gets angry at Adem for coming home with his friends on the very night she is preparing a drawing for a major company presentation. She then continues her work, trying not to pay any attention to them, although she has resentment towards Adem. In the meantime, Adem gets excited about a score in the game and throws his arms around her neck, causing the coffee in Didem's hands to spill down on the drawing. While trying to clean up the coffee stain, Adem mistakenly destroys a part of the drawing as well. Didem just watches what has become of her project, which she has worked on for such a long time, in utter shock. Adem apologizes over and over again. Didem can't even react, not knowing what to do. Didem has a presentation the next day and has to show the drawing with the coffee stain on it hoping that she can possibly fix it. The following day, both 
Adem and Didem go to work. Didem makes her presentation that day and it does not go as well as she had hoped. She returns home sad. She secretly blames Adem. Up until that point, they had moved to several cities all because of Adem's wishes. Didem always encountered difficulty in making progress at work due to this, although she could have become very successful. Adem comes home in the evening and tells Didem everything he had done that day. He continuous to speak about himself. In the meantime, Didem listens to him in a still and unresponsive manner. Adem understands later that Didem was sad and unresponsive, at which point Didem becomes sad again. Didem sees that the person in front of her didn't even remember to ask about her presentation and she becomes grieved. This is the dialogue between Didem and Adem the evening after the presentation:

Didem: My presentation was awful and I was disgraced before everyone.

Adem: You haven't been at your job for years, it is possible.

Didem: It was awful because of you. I am a capable woman. You have been dragging me behind you for seven years. We went to Ankara. You didn't want to be there. We couldn't stay so we returned. You said that you missed your father; we moved to Ağrr. Then you said you missed football, going to matches, music, and we packed up everything and returned again. Your father, your friends, your family, your life, your job! I am a servant to your bachelor life. Tell me, what am I to you?

Adem eases off after this angry response from Didem. He shows development and understanding for Didem for the first time, even if it isn't much. He realizes what she feels and how much she has grown sad because of him. He apologizes to her, hugs her, cries, and makes promises for the future. At this stage, the unhealthy attitude and behavior belongs to Adem, not Didem, as stated by Whitaker. This attitude of Didem creates a milestone in their marriage, causing Didem to take her reaction and problem from herself and extend the symptom to include Adem for the first time in the marriage for which she has battled by herself for so long. This becomes a great development for their marriage.

Marriage Bigger Than its Parts: According to Whitaker, marriage is bigger than the sum of its parts. It is a systemic belief that the whole is always more than the sum of its parts. An example of this is to consider marriage as a cake. The fact that eggs cannot be excluded from an already baked cake is a good metaphor for this (Whitaker, Greenberg, \& Greenberg, 1979 as cited in Martin, 2011). At this stage, the hypothesis which was grounded on Gestalt Therapy suggests that the whole always has a different and separate meaning than its parts.

Upon looking at the film from the beginning, the first person who considers the marriage as bad and not going well is Didem. Piled-up resentments and Didem's annoyances cause bursts of rage. However, Adem cannot take the steps to make Didem happy. Even when he tries to take such steps, the spell is broken due to misunderstandings and eventually the marriage process becomes a dead-end block for both parties. Several times, Didem tries to speak to Adem. She tries to express her resentments and disappointments by getting angry or showing resentment from time to time. However, Adem shuffles his feet in response to fulfilling Didem's requests. He continues to focus on himself, doing the things that Didem does not like. Adem believes that such a change is not a requirement and that Didem has difficulty accepting him as who he is. As a result, healthy communication becomes increasingly interrupted. Eventually they become two individuals who are angry and furious at each other in spite of living under the same roof. Didem leaves home since they cannot find a solution, and she suffers increasingly worse experiences after all of the exhausting quarrels and fluctuations. Although Adem became sad at the beginning, he believes that this was the right thing to do. In a similar fashion, Didem also thinks that they must break up, even if she does become sad. Even though there are moments when they feel they miss each other a lot during this period of separation, they convince themselves that breaking up would be the reasonable thing to do. Both of them feel empty and experience depression from time to time; neither of them feels good about getting accustomed to the separation process. However, Adem files for divorce, believing that a decision needs to be made after all. Although Didem expects it, the divorce request nevertheless appalls her. However, she believes that she needs to get used to this situation and continue with her life. Therefore, Didem commits herself to her work. She starts to realize her boss has an interest in her, but it is not enough to make her happy. At this stage, Didem starts to increasingly miss Adem, remembering her good memories with Adem and understanding that she could never look upon anyone but Adem with affection. She cannot fall in love or love anyone else but him. Adem's initial anger at Didem leaving the house diminishes. He suffers deeply from the 
Didem's absence. He locks himself in the house, stops seeing his friends, and isolates himself from everything. In fact, even though Adem initially sets forth in confidence, believing that the divorce would do him good, he starts to realize that he has made a mistake. He starts to miss Didem and feels alone and unhappy as time passes by.

At this stage, the deep commitment and love of spouses towards each other is realized only when looking at the whole of the marriage, which in its parts has basically progressed problematically with merely an outlook of problems. Although there are problems at this point in the marriage which are addressed in the film, it can be seen that it embodies a very strong commitment and love.

Blind Marriage: According to Whitaker, marriage is blindness in both legal and emotional terms. Marriage restricts two people from approaching other individuals outside the marriage emotionally. It also restricts them legally for fidelity (Whitaker, Greenberg, \& Greenberg, 1979 as cited in Martin, 2011). In this respect, marriage can place people in a restricted life, which can lead them to become mentally depressed, causing problems to arise in marriages.

Upon looking at the scenes in the film, it can be seen that this hypothesis is in fact a structure which is preached to the subconscious by one's environment. It can be thought that maintaining a marriage or relationship with only one person can make overcoming the innate impulse of sexuality difficult. At this stage, one can also only prefer one sex life through monogamy. However, humans can look at other people and desire them. One of the most striking scenes of the movie which is in compliance with this discourse follows. While Adem is working at his clinic one day, a very sexy woman enters and speaks in a manner to entrance Adem. Although Adem is influenced by the attitude of the woman, he does not pursue it. The woman repeatedly calls Adem and disturbs him. However, Adem responds to these calls professionally. One of Adem's close friends who is aware of this says to Adem, "Man, this woman has fallen for you, are you stupid enough not to see this?" Adem responds, "I love Didem very much. I am married." His friend says, "You are one of the rare monogamous people. Being with only one woman for 18 years and married with her for seven years, too. Man, you are right in the middle of the syndrome." In fact, Adem's friend expects him to be able to live with the freedom to look at other women as well as leave from the blindness of marriage. It can be seen from the non-verbal behaviors of Adem that he is influenced by the woman's physical attractiveness, yet he tells his friend that he is in love with Didem and cannot do such a thing to his spouse because of the promise he had made for the union of marriage.

Marriage is often seen as one of the basic stages of life in Turkish culture. Similar to other structures, marriage is also formed according to the cultural structure and value judgments of the society it stands for (Sezen, 2005). In all societies, families are bound to certain rules by marriage. These rules manifest themselves in various areas from selecting a spouse to where the married couple will settle (Altuntek, 2001). From this perspective, culture is a structure which can contain the expectations of how men and women should think, behave, and act as well as the expectations concerning mixedgender judgments. In this structure, the various roles of women and men can take on different dimensions in terms of sexuality as well (Civil \& Yildiz, 2010). Although a section of our society can accept blind marriage due to these reasons, it can be said that stepping out of this structure could create a structure which inflicts greater harm on marriages and the institution of marriage. This can possibly be associated with the uneasiness of living one's sexuality in Turkish culture.

Customs and traditions, taboos, religious rules, and prejudices were the determinant of the majority of sexual behavior both in the world and in Turkey (Civil \& Y1ldız, 2010). Considering religious orientation and other value judgments in our society, it does not quite seem possible for it to accept the blindness of marriage as it has a structure of belief which often stipulates that one must get married to have a legitimate sex life, and that talking about or experiencing sexuality should be kept confidential. It can prove more useful to progress with this judgment in a semi-collective society for the continuance of order.

Flexibility of Roles: Separating the roles of generations is only possible through the availability of flexible roles. According to Whitaker and Keith (1980), a father should be able to become a five-year old child; a mother should be able to become a threeyear old child; and a three-year old child should be able to become a father or mother. Healthy families can distinguish between the statements "This is a game, it is not real" and "This is not a game, it is real” (Keith, Kaye, \& Dichter, 1986). When looked at from this perspective, the strict roles in a family can prove difficult for the functioning of a family. Therefore, flexibility of roles can provide family members with the opportunity to create more 
comfortable living zones. The same should apply to the system between spouses as well. Whitaker defines family as a structure which includes three or four generations. Whitaker has an acquired historical perspective concerning the relationship among family members and the relationship among family sub-systems. Accordingly, equality cannot often be achieved among children, husband, and wife in the areas of authority and responsibility (Dhanesar, 2006). However, the flexibility of roles is emphasized in a healthy family. At this stage, the balance of power should be flexible and family members (each woman, man, and child) should be able to simultaneously behave free and individually in respect to belonging to the family the way they want (Nichols, 1984 as cited in Dhanesar, 2006). In this perspective, it can be said that spouses can have a healthier family structure when they are flexible with their roles. At this stage, Whitaker states that healthy families can have greater control on stress levels, further enhance the bonds which increase the development and growth of a family, be more open to new experiences, and can develop their repertoire of information and behavior thanks to this flexibility (Whitaker, 1989 as cited in Dhanesar, 2006).

Upon looking at the scenes in the film, it is seen that the family is comprised of two people. Due to the fact that no parent role exists yet, the family structure constitutes the roles of husband and wife. Although an entirely traditional structure based on very specific gender roles is not seen at this stage, it can be said that Didem is more responsible for house chores and is the person who deals with situations such as cooking and cleaning, while Adem is more autonomous, lives a life of his own free will, does not assume the responsibility of the house as much as Didem, and leaves other duties to Didem due to the fact that he has assumed the role of bringing money home. At this stage, as a person who has impeded Didem's life, he tells Didem in a scene, "In fact, you can quit work. I am taking care of both of us. You don't have to work. Come back home." At this stage, the preciseness of his role, which already exists, is more clearly seen. According to the perspective of Adem, the place of a woman should be at home while the place of a man should be at work. For a healthy family structure, women should be able to undertake what is seen as men's work and a man should be able to fulfill those seen as women's work. Therefore, both parties can feel themselves more supported.

\section{Conclusion and Suggestions}

In this study, various scenes from the film "Ya Sonra" are explained using the concepts of emotional deadness, pathology as symptom of development, the focus person of the problem in the family, marriage greater than its parts, blind marriage, and flexibility of roles. This analysis attempts to set forth various aspects of Whitaker's non-theoretical approach more clearly. Based on the knowledge that Whitaker's approach, as frequently mentioned in the literature, is an approach which is difficult to learn and therefore difficult to practice, it is possible to mention the difficulty of applying this approach to film analysis. As an approach in which the theoretical perspective of therapy is strongly influenced by the personality and individuality of the therapist, the analysis can certainly vary among individuals. It seems particularly difficult for an approach grounded in concepts such as spontaneity, creativity, craziness, and absurdity to reach the functionality of western countries in countries with extremely semi-collectivist social structures as in Turkey. As a country which takes new steps in the field of family therapy and makes attempts to open undergraduate and graduate programs in this field, this "absurd" approach, as compared to other traditional approaches, can prove difficult to apply clinically in Turkey. It is thought at this stage that this analysis will enlighten family therapists and students who receive education in family therapy. It gives an opportunity to allow this approach, which is a nontraditional approach with questioned practicability and limited informational literature, to be known more closely.

In general, visual depictions including film analysis offer strong instruments for research and they construct reality rather than simply define it (Rose, 2011 as cited in Orhan, 2010). Although films are not considered as the ultimate research data for scientific research, they are a reflection of social practices just as their representations (Orhan, 2010). Therefore, it is possible to access various cultural data through film. That is why a perspective into Turkish culture in respect to both marriage and family therapy could be presented, particularly to pragmatists in the field, through film analysis. From this perspective, it is demonstrated that it could be possible to work with spouses or families undergoing family and marriage therapy using methods such as stories, metaphors, and symbols in an atmosphere outside of the ordinary sessions to some degree, distant from structuralism and spontaneous. The availability of several resources for using stories and creativity in the cultural sense reinforces the practicability of this therapy from this aspect. 
Additionally, certain films can be used as auxiliary resources in therapeutic processes within the framework of movie therapy (Acar \& Voltan-Acar, 2013). Based on this information, films can be used in couples therapy processes within the fields of marriage and family therapy. For the next stages, the film "Ya Sonra" can take its place among the

\section{References}

Acar, T., \& Voltan-Acar, N. (2013). "Babam ve Oğlum" filminin çok kuşaklı/kuşaklararası aile terapisinin temel kavramları açısından değerlendirilmesi. Kuram ve Uygulamada Ĕ̆itim Bilimleri, 13, 37-53.

Altuntek, S. (2001). Türkiye üzerine yapılmış evlilik ve akrabalık araştırmalarının bir değerlendirmesi. Hacettepe Üniversitesi Edebiyat Fakültesi Dergisi, 18(2), 17-28).

Banker, J. E. (2008). Family clay sculpting. Journal of Family Psychotherapy, 19(3), 291-297. doi:10.1080/08975350802269533

Bermudez, J. M. (1997). Experiential tasks and therapist bias awareness. Contemporary Family Therapy, 19(2), 253267. doi:10.1023/A:1026123303796

Carson, D. K. (1999). The importance of creativity in family therapy: A preliminary consideration. The Family Journal: Counseling and Therapy for Couples and Families, 7(4), 326-224. doi:10.1177/1066480799074002

Civil, B., \& Yıldız, H. (2010). Erkek öğrencilerin cinsel deneyimleri ve toplumdaki cinsel tabulara yönelik görüşleri. Dokuz Eylül Üniversitesi Hemşirelik Yüksekokulu Elektronik Dergisi, 3(2), 58-64.

Cullin, J. (2008). Method in maddness: The strategic uses of absurdity and the unexpected in psychotherapy. Australian and New Zealand Journal of Family Therapy, 29(4), 191200. doi:10.1375/anft.29.4.191

Dermer, S. B., \& Hutchings, J. B. (2000). Utilizing movies in family therapy: Applications for individuals, couples and families. The American Journal of Family Therapy, 28, 168180. doi:10.1080/019261800261734

Dhanesar, S. T. N. (2006). A different kind of therapy: An analysis of the symbolic experiential therapy of Carl Whitaker, M.D. as interpreted through the lens of a systems thinker (Doctoral dissertation). Avaliable from ProQuest Dissertations and Theses database. (UMI No. 3248153)

Durak, E. Ş., \& Fışıŏlu, H. (2007). Film analizi yöntemi ile Virginia Satir' in aile terapisi yaklaşımına bir bakış. Türk Psikoloji Yazıları, 10(20), 43-62.

Gladding, S. T. (2007). Family Therapy: History, theory and practice. New Jersey, NJ: Pearson Merrill Practice Hall.

Gladding, S. T. (2012). Aile terapisi: Tarihi, kuram ve uygulamaları (trans. eds. İ. Keklik \& İ. Yıldırım). Ankara: Türk Psikolojik Danışma ve Rehberlik Derneği Yayınları.

Goldenberg, H., \& Goldenberg, I. (2008). Family therapy: An overview. Pacific Grove, CA: Thomson Higher Education. exemplary films which can be used by psychological counselors who study in the fields of marriage and family therapy. At the same time, this film can be evaluated from the perspective of different theories to give an idea concerning the marriage structure of Turkish culture, and it can be reanalyzed using different concepts.
Horzum, I. (2011). Dövüș Kulübü filminin ruhbilimsel çözümlemesi. Akademik Bakış Dergisi, 25, 1-24.

Keith, D., Kaye, D., \& Dichter, H. (1986). Symbolicexperiential family therapy. Individual Psychology: Journal of Adlerian Theory, Research \& Practice, 42(4), 521-536.

Martin, A. (2011). Symbolic-experiential family therapy. In L. Metcalf (Ed.), Marriage and family therapy: A practiceoriented approach (pp. 147-175). New York, NY: Springer Publishin Co.

Mitten, T. J. (1996). A conceptual framework for symbolicexperiential therapy: Extension of the apprenticeship model (Doctoral dissertation). Avaliable from ProQuest Dissertations and Theses database. (UMI No. 9713565)

Mitten, T., \& Piercy, F. P. (1993). Learning symbolicexperiential therapy: One approach. Contemporary Family Therapy, 15(2), 149-168. doi:10.1007/BF00892453

Mitten, T. J., \& Connell, G. M. (2004). The core variables of symbolic-experiential family therapy: A qualitative study. Journal of Marital and Family Therapy, 30(4), 467-478. doi:10.1111/j.1752-0606.2004.tb01256.x

Nadir, U. (2013). Aile danışmanlığı eğitimlerinde popüler filmlerin kullanımı ve yapisal aile terapisi kuramı ile dalgaların prensi filminin analizi. Toplum ve Sosyal Hizmet, 24(1), 129-143.

Neill, J. R., \& Kniskern, D. P. (Eds.). (1989). From psyche to system: The evolving therapy of Carl Whitaker. New York, NY: Guilford Press.

Orhan, K. (2010). "Modern Zamanlar" filmi ve dönemsel bir çalışma ilişkileri yorumlaması. Çalıșma ve Toplum, 1, 133-152.

Powell, M.L. (2008). Cinematherapy as a clinical intervention: Theoretical rationale and empirical credibility (Doctoral dissertation). Avaliable from ProQuest Dissertations and Theses database. (UMI No. 3341245)

Sezen, L. (2005). Türkiye'de evlenme biçimleri. Atatürk Üniversitesi Türkiyat Araştırmaları Enstitüsü Dergisi, 27, 185-195.

Smith, G. L. (1998). The present state and future of symbolic-experiential family therapy: A post-modern analysis. Contemporary Family Therapy, 20(2), 147-161. doi:10.1023/A:1025073324868

Sugarman, S. (1987). Teaching symbolic-experiential family therapy: The personhood of the teacher. Contemporary Family Therapy, 9(1-2), 138-145. doi:10.1007/BF00890269 
Thompson, S. J., Bender, K., Cardoso, J. B., \& Flynn, P. M. (2011). Experiential activities in family therapy: Perceptions of caregivers an youth. Journal of Child and Family Studies, 20(5), 560-569. doi:10.1007/s10826-010-9428.

Villalba, J. A., \& Redmond, R. E. (2008). Crash: Using a popular film as an experiential learning activity in a multicultural counseling course. Counselor Education \& Supervision, 47, 264-276. doi:10.1002/j.1556-6978.2008. tb00056.x

Wedding, D., \& Niemiec, R. M. (2003). The clinical use of films in psychotherapy. Psychotherapy in Practice, 59(2), 207-215. doi:10.1002/jclp.10142
Whitaker, C. A. (2000). Hypnosis and depth therapy. The Family Journal, 8(7), 7-13. doi:10.1177/1066480700081003

Whitaker, C. A., \& Keith, D. V. (1980). Family therapy as symbolic experience. International Journal of Family Psychiatry, 1, 197-208.

Wilson, A. H., Blake, B. J., Taylor, G. A., \& Hannings, G. (2013). Cinemeducation: Teaching family assessment skills using full-length movies. Public Health Nursing, 30(3), 239245. doi: $10.1111 / \mathrm{phn} .12025$ 